\title{
ESTUDO MICROBIOLÓGICO EM CARCAÇAS BOVINAS E INFLUÊNCIA DA REFRIGERAÇÃO SOBRE A MICROBIOTA CONTAMINANTE
}

\section{C.L. Fontoura, O.D. Rossi Júnior, T.M. Martineli, N.D. Cereser}

Universidade Estadual Paulista, Faculdade de Ciências Agrárias e Veterinárias, Departamento de Medicina Veterinária Preventiva e Reprodução Animal, Via de Acesso Prof. Paulo Donato Castellane, km 5, CEP 14884900, Jaboticabal, SP, Brasil. E-mail: fontouravet@yahoo.com.br

\section{RESUMO}

\begin{abstract}
Objetivando avaliar a presença de micro-organismos indicadores e de estafilococos em carcaças bovinas e a influência da refrigeração sobre a microbiota contaminante, foram analisadas amostras de regiões da superfície externa de meias carcaças tais como coxão, lombo e ponta-deagulha, logo após a lavagem e após 24 horas sob refrigeração. As médias das populações de microorganismos heterotróficos mesófilos, psicrotróficos e Staphylococcus sp. em UFC $/ \mathrm{cm}^{2}$ obtidas imediatamente após a lavagem apresentaram valores respectivamente de $1,8 \times 10,6,4$ x 10 e 3,5 $x 10 \mathrm{UFC} / \mathrm{cm}^{2}$, enquanto que para as amostras colhidas após refrigeração os valores foram de 1,3 $\times 10,1,6 \times 10^{2}$ e 5,2 x $10 \mathrm{UFC} / \mathrm{cm}^{2}$. As populações foram consideradas reduzidas, decorrentes de eficientes cuidados higiênicos sanitários durante as operações de abate, e as diferenças observadas entre as médias dos dois grupos de amostras não foram significativas do ponto de vista estatístico, o que permite concluir que não houve aumento considerável da população microbiana, demonstrando a eficiência do processo de refrigeração em seguida ao abate.
\end{abstract}

PALAVRAS-CHAVE: Carcaça bovina, micro-organismos indicadores, Staphylococcus sp.,refrigeração.

\section{ABSTRACT}

MICROBIOLOGICAL STUDY IN BOVINE CARCASSES AND THE INFLUENCE OF REFRIGERATIONONCONTAMINATING MICROBIOTA. With the aim of evaluating the presence of microorganisms in bovine carcasses and the influence of refrigeration on the contaminating microbiotics, some samples were collected from the outer surface of half-carcasses in these regions (rump, loin and rib), after washing and after 24 hours under refrigeration. The average of the mesophilic heterotrofic, psychrotrofic and Staphylococcus microorgarnisms, obtained immediately after the carcass washing were respectively $1.8 \times 10,6.4 \times 10$ and $3.5 \times 10 \mathrm{CFU} / \mathrm{cm}^{2}$, while for the samples collected after refrigeration these values were $1.3 \times 10,1.6 \times 10^{2}$ and $5.2 \times 10 \mathrm{CFU} / \mathrm{cm}^{2}$. The populations were considered low due to the hygienic practices during the slaughter process, and the differences observed between the averages of the two groups of samples were not statistically significant, leading to the conclusion that that was not an increase of the microorganism population, thus demonstrating the efficacy of the refrigeration process after the slaughter.

KEY WORDS: Bovine carcass, indicator microorganisms, Staphylococcus sp., refrigeration.

\section{INTRODUÇÃO}

A carne, por suas características intrínsecas, como composição química, elevada atividade deágua e $\mathrm{pH}$ próximo à neutralidade, é um ótimo meio para a multiplicação de micro-organismos. Assim, conhecer e prevenir a presença de micro-organismos que encontram na carne um ambiente propício para a sua proliferação constituem fatores determinantes para a preservação de sua qualidade.

Considerando que os micro-organismos estão amplamente distribuídos no ambiente de matadou- ros-frigoríficos e que a instalação e proliferação de agentes microbianos na musculatura, sobretudo bactérias, iniciam-se em seguida à introdução de facas não esterilizadas no sistema vascular, cuidados especiais de ordem higiênico-sanitária devem ser atribuídos em todas as etapas de obtenção da carne, visando reduzir falhas tecnológicas para a sua inocuidade.

Após a sangria e quando o animal deixa de apresentar movimentos reativos, inicia-se a esfola, a qual se constitui em um dos primeiros pontos críticos do abate, tendo em vista as possibilidades de contamina- 
ção da superfície das carcaças a partir de microorganismos existentes na pele, nos pêlos e cascos dos animais (LAMBERT et al., 1991). Nas fases seguintes, representadas pela evisceração e toalete, estas contaminações podem se acentuar, comprometendo a qualidade microbiológica das carcaças, pelo aumento da população microbiana nas suas superfícies externa e interna.

Dentre os procedimentos operacionais do abate está também a lavagem, em que as meias carcaças são submetidas a jatos d'água, geralmente à temperatura em torno de $38^{\circ} \mathrm{C}$, sob pressão mínima de $3 \mathrm{~atm}$, com o objetivo de eliminar esquírolas ósseas, coágulos, pêlos e outros materiais estranhos aderidos à superfície (Roça; Serrano, 1994). Neste sentido, Dickison (1988) conclui que a lavagem pode reduzir a carga microbiana superficial da carcaça, dependendo da temperatura, pressão, volume de água e presença de sanitizantes. Por outro lado, MADDEN et al. (2004) demonstraram que, por consequência de cuidados inadequados nas práticas de produção, a lavagem pode distribuir os micro-organismos da parte posterior para a anterior das meias carcaças.

Segundo ZWEIFEL;STEPHAN (2003), a quantificação da população de micro-organismos aeróbios mesófilos das superfícies das carcaças é comumente utilizada para fornecer dados que indiquem o grau de cuidados higiênico-sanitários adotados durante as operações de abate. Outro grupo de extrema importância para a avaliação da qualidade e da perspectiva da vida comercial de carnes armazenadas e comercializadas sob refrigeração é representado pelos micro-organismos psicrotróficos (GIL, 2002).

Além de micro-organismos mesófilos e psicrotróficos, outros agentes como enterobactérias e estafilococos podem ser encontrados em superfícies de carcaças bovinas. DESMARCHELIERet al. (1999) verificaram a presença de Staphylococcus coagulase positivo em algumas regiões da musculatura como peito e flanco e, segundo Le LoIR et al. (2003), a presença deste grupo de microrganismos nos produtos de origem animal e em condições apropriadas, pode levar à produção de enterotoxinas e, consequentemente, à possibilidade de casos de intoxicação alimentar pelo consumo destes.

De acordo com GARCiA-Lopes et al. (1998), a rapidez de decomposição das carcaças depende do seu teor em micro-organismos psicrotróficos, da temperatura de armazenamento e da atividade de água superficial. A deterioração da carne tem seu início quando a população de psicrotróficos esta na faixa de $10^{6} \mathrm{UFC} / \mathrm{g}$, resultando em defeitos físicos como a descoloração da superfície; entre $10^{7}$ e $10^{8} \mathrm{UFC} / \mathrm{g}$ surgem odores estranhos e em contagens por volta de $10^{9} \mathrm{UFC} / \mathrm{g}$ aparece o limo superficial (RoçA; SERRANO, 1995).
Considerando a relevância do exposto, o presente estudo teve como objetivo avaliar as condições microbiológicas de meias-carcaças de bovinos após a etapa de lavagem e após 24 horas de permanência na câmara de resfriamento, através da quantificação de micro-organismos mesófilos, psicrotróficos e Staphylococcus coagulase positivos.

\section{MATERIAL E MÉTODOS}

Estudou-se a superfície muscular de 40 meias carcaças logo após a lavagem e após 24 horas de permanência em câmara de resfriamento a $0^{\circ} \mathrm{C}$. Amostras destas meias carcaças foram obtidas através de suabes aplicados na região do coxão, lombo e ponta de agulha em áreas de $20 \mathrm{~cm}^{2}$ em cada ponto, utilizando-se para a demarcação um gabarito em aço inoxidável (APHA, 2001). As amostras foram coletadas em um matadouro-frigorífico situado no Estado de São Paulo, com capacidade de abate em torno de 950 bovinos/dia, submetidoa programas deautocontrole como procedimento padrão de higiene operacional, análise de perigos e pontos críticos decontrole, dentre outros, com inspeção federal permanente.

As análises microbiológicas foram realizadas no Laboratório de Análise de Alimentos de Origem Animal e Água do Departamento de Medicina Veterinária Preventiva e Reprodução Animal da Faculdade de Ciências Agrárias e Veterinárias, Câmpus de Jaboticabal, Unesp.

Para contagem padrão em placas de micro-organismos heterotróficos aeróbios ou facultativos, mesófilos e psicrotróficos viáveis (APHA, 2001; ICMSF, 2000) primeiramente foram preparadas diluições decimais da solução de transporte dos suabes $\left(10^{0}\right)$, sendo a inicial $\left(10^{-1}\right)$ obtida a partir da mistura de $1 \mathrm{~mL}$ da referida solução com $9 \mathrm{~mL}$ da água peptonada a $0,1 \%$. Diluições sucessivas até $10^{-3}$ foram preparadas utilizando-se o mesmo diluente. Em seguida $1 \mathrm{~mL}$ da solução de transporte e de cada diluição foi depositado no fundo de placas de Petri esterilizadas, em duplicata, distribuídas em duas séries, às quais foi adicionado ágar padrão para a contagem fundido e resfriado a temperatura em torno de $45^{\circ} \mathrm{C}$. Após homogeneização e solidificação do ágar em temperatura ambiente, uma série de placas foi incubada a $37^{\circ} \mathrm{C}$ por 48 horas para a contagem de mesófilos e a outra série foi incubada a $7^{\circ} \mathrm{C}$ por 10 dias em incubadora para B.O.D., para a contagem de psicrotróficos. As contagens foram realizadas em contador de colônias, segundo a técnica padrão, em placas que apresentavam de 25 a 250 unidades formadoras de colônias.

Para a contagem de Staphylococcus coagulase positivo (APHA, 2001; ICMSF, 2000) foram utilizadas 
diluições de $10^{\circ}$ a $10^{-2} \mathrm{e}$, a partir delas, retirados 0,2 $\mathrm{mL}$ e depositados em placas com ágar Baird-Parker. Os inóculos foram distribuídos por toda a superfície do meio e as placas incubadas a $35^{\circ} \mathrm{C}$ por 24 a 48 horas. Após a incubação, foram contadas as colônias negras, brilhantes, com ou sem zona de precipitação ao redor e circundadas ou não por halo claro, nas placas contendo 20 a 200 colônias.

A seguir, 3 a 5 colônias de cada tipoforam semeadas em tubos com ágar nutrienteinclinado os quais foram incubados $\mathrm{a} 35^{\circ} \mathrm{C}$ por 24 horas para a preparação dos esfregaços pelo método de Gram. As culturas que se apresentaram em forma de cocos Gram-positivos e agrupadas em forma de cachos de uva foram submetidas às provas da catalase e oxidação e fermentação da glicose $(\mathrm{O} / \mathrm{F})$, para a confirmação do gênero. As cepas que apresentaram resultados positivos nestas provas foram submetidas à prova da coagulase livre. Para tal foram semeadas em tubos contendo caldo de infusão de cérebro e coração (BHI), e incubadas a $35^{\circ} \mathrm{C}$ por 24 horas. Após esta etapa, acrescentou-se, em tubos de ensaio, $0,3 \mathrm{~mL}$ desta cultura e $0,5 \mathrm{~mL}$ de plasma citratado de coelho diluído um para cinco. Após agitação os tubos foram incubados em banhomaria a $37^{\circ} \mathrm{C}$ e as leituras realizadas após 1, 2, 3, 4 e 24 horas.

A análise estatística foi efetuada por meio da comparação entre as médias das populações dos grupos microbianos quantificados na superfície das carcaças imediatamente após a lavagem e depois de 24 horas sob refrigeração, utilizando o teste " $\mathrm{t}$ " de Student (DowdY; WEARDEn, 1991).

\section{RESULTADOS E DISCUSSÃO}

Na Tabela 1 estão apresentadas as médias das populações de micro-organismos heterotróficos mesófilos, psicrotróficoseStaphylococcussp.,emUFC/ $\mathrm{cm}^{2}$, obtidas a partir de amostras da superfície de carcaças bovinas colhidas imediatamente após a lavagem e após 24 horas sob refrigeração, bem como o resultado da análise estatística através do teste " $t$ ". É importante salientar que não foram identificados Staphylococcus coagulase positivos.

Para as amostras colhidas imediatamente após a lavagem os valores médios foram, respectivamente, de $1,8 \times 10,6,4 \times 10$ e $3,5 \times 10 \mathrm{UFC} / \mathrm{cm}^{2}$, enquanto que para as amostras colhidas após a refrigeração estes valores foram $1,3 \times 10,1,6 \times 10^{2}$ e $5,2 \times 10 \mathrm{UFC} / \mathrm{cm}^{2}$. Os valores de " $\mathrm{t}$ " $=0,49^{\mathrm{NS}},-1,72^{\mathrm{NS}},-1,00^{\mathrm{NS}}$ demonstram não haver diferença estatisticamente significativa $(p>0,05)$ entre as médias das populações dos grupos microbianos estudados na superfície de carcaças imediatamente após a lavagem eapós 24 horas sob refrigeração.
MADDEn et al. (2004) quantificaram micro-organismos mesófilos em 100 carcaças bovinas e verificaram resultados médios de $2,8 \times 10^{3} \mathrm{UFC} / \mathrm{cm}^{2}$ após a lavagem, resultado este superior ao encontradono presente estudo $\left(1,8 \times 10 \mathrm{UFC} / \mathrm{cm}^{2}\right)$. Os autores concluíram que a lavagem das carcaças quando realizada com água fria é um método ineficaz na remoção microbiana da superfície, podendo redistribuir contaminantes para partes ainda não contaminadas. Embora o presente estudo tenha utilizado apenas jatos de água com temperatura em torno de $38^{\circ} \mathrm{C}$ para a lavagem, não se pode afirmar se houve redistribuição. Todavia, o presente estudo considera a importância da higiene durante todo o abate a fim de evitar a contaminação cruzada.

Sumner et al. (2003) avaliaram a população de micro-organismos heterotróficos mesófilos após a refrigeração das carcaças e também encontraram valores próximos aos do presente estudo, sendo 1,82 $\mathrm{UFC} / \mathrm{cm}^{2}$. No entanto, SoFos et al. (1999) verificaram que os níveis de contaminação nas carcaças após 24 horas na câmara de resfriamento foram de 3,5 x $10^{2}$ $\mathrm{UFC} / \mathrm{cm}^{2}$ para contagem de micro-organismos aeróbios mesófilos, resultado este superior ao valor médio da população encontrada no presente estudo $\left(1,3 \times 10 \mathrm{UFC} / \mathrm{cm}^{2}\right)$.

PHILLIPS et al. (2001) encontraram valores médios de mesófilos de 2,6 $610^{2} \mathrm{UFC} / \mathrm{cm}^{2}$. Segundo os autores, provavelmente os valores médios elevados encontrados podem ser atribuídos ao tempo de permanência das carcaças na câmara de resfriamento, o qual foi de 12 horas e a alguma falha operacional durante o resfriamento. No presente estudo, a permanência das carcaças na câmara de resfriamento foi de 24 horase, talvez, as falhas operacionais tenham sido menores, uma vez que as amostras apresentaram valores médios inferiores aos obtidos por aqueles autores.

De acordo com Ingram; RoberTs (1976), a determinação da população de micro-organismos psicrotróficos na superfície da carne é utilizada para verificar a manutenção da qualidade da carne refrigerada, uma vez que estes micro-organismos são capazes de se multiplicarem sob temperatura de refrigeração.

BARRA (1980) observou em um frigorífico que os quartos dianteiros continham em média mais psicrotróficos $\left(5,0 \times 10^{6} \mathrm{UFC} / \mathrm{g}\right)$ que os quartos trasei$\operatorname{ros}\left(1,0 \times 10^{6} \mathrm{UFC} / \mathrm{g}\right)$. Apesar dos diferentes locais de amostragem e métodos de avaliação do estudo citado em relação ao atual, verifica-se na Tabela 1 que a população de micro-organismos psicrotróficos apresentou resultado inferior.

Mesmo não havendo uma legislação específica e obrigatória para a determinação da população de microrganismos heterotróficos psicrotróficos, notase neste estudo que, tanto após a lavagem quanto após 24 horas sob refrigeração, as médias das populações 
de micro-organismos psicrotróficos encontradas foram de $6,4 \times 10$ e 1,6 $610^{2} \mathrm{UFC} / \mathrm{cm}^{2}$, estando a uma distância considerável do início da deterioração $\left(10^{6}\right.$ UFC/g) constatado por RoçA; SERRANo (1995).

Segundo PORTO(1997), o prazo máximo de vida-deprateleira da carne resfriada varia de acordo com a contaminação inicial do produto, estimando o prazo para quatorze dias quando a contagem inicialé de $10^{2}$ UFC/g. O resultado apresentado no atual estudo permite estimar uma vida-de-prateleira do produto aproximada de quatorze a quinze dias.

Embora a enumeração de Staphylococcuscoagulase positivos nos alimentos não seja uma técnica específica, é um efetivo indicador do grau de contaminação com cepas potencialmente patogênicas (Desmarchelier et al., 1999), fazendo-se necessário a adoção de práticas de higiene em todas as etapas de obtenção da carne, para reduzir as possibilidades de contaminações.

DESMARCHELIERet al. (1999) isolaramStaphylococcus coagulase positivos em $43 \%$ das carcaças bovinas após a lavagem. No presente estudo não houve identificação de cepas de Staphylococcus coagulase positivos, podendo-se considerar o resultado como satisfatório, salientando que no estabelecimento estudado era quase nula a rotatividade dos funcionários envolvidos no abate, o que contribui para um melhor controle e redução da contaminação cruzada.

Em 465 carcaças analisadas, VANDERLINDE et al. (1998) verificaram que após 24 horas sob refrigeração houve um aumento de $27,7 \%$ na população de Staphylococcus coagulase positivos. No presente estudo pode-se observar (Tabela 1) que o aumento na população de Staphylococcus sp. após refrigeração foi relativamente pequeno. No entanto, é importante ressaltar que a refrigeração apenas retarda o desenvolvimento dos micro-organismos.

PHILlips et al. (2001) avaliaram a qualidade microbiológica de carcaças bovinas (região da cauda, flanco e peito) e verificaram que dentre 1.275 amostras de carcaças coletadas após 12 horas sob refrigeração, 24,3\% continham Staphylococcus coagulase positivos. Os autores concluíram que o método de Análise de Perigos e Pontos Críticos de Controle (APPCC) foi capaz de assegurar, com mais eficácia, a qualidade da carne nas diferentes etapas de obtenção. Pelo fato de não terem sido identificados Staphylococcus coagulase positivos no presente estudo, pode-se afirmar que as técnicas consideradas como pré-requisitos para a implantação do sistema APPCC apresentavam poucas falhas operacionais.

Embora no presente estudo não tenha sido detectado Staphylococcus coagulase positivos, a simples presença de representantes do gênero Staphylococcus não pode ser desconsiderada. Segundo Rosec et al. (1997), há uma gama de cepas coagulase negativas produtoras de enterotoxinas, sendo recomendado que as indústriaseórgãos fiscalizadores também se preocupem com os Staphylococcus coagulase negativos.

Diante dos resultados obtidos pode-se concluir que as médias das populações de micro-organismos heterotróficos mesófilos, psicrotróficos e Staphylococcus sp. foram inferiores à da literatura pesquisada, observando quea temperatura de refrigeração, aliada a eficiência nos cuidados higiênicosanitários e tecnológicos durante as operações de abate, impediu o desenvolvimento microbiano, mostrando que é possível obter produtos com maior vidade-prateleira e de ótima qualidade do ponto de vista microbiológico, uma vez que, os programas de autocontrole sejam corretamente implantados e obedecidos para a comercialização dealimentos seguros, saudáveis e inócuos aos consumidores.

\section{REFERÊNCIAS}

APHA. AMERICANMERICAN PUBLIC HEALTH ASSOCIATION. Committee on Microbiological Methods for Foods. Compendium of methods for the microbiological examination of foods. 4.ed. Washington: APHA, 2001. 676p.

Tabela 1 - Valores médios das populações de micro-organismos heterotróficos mesófilos, psicrotróficos eStaphylococcus sp., bem como os resultados do teste " $\mathrm{t}$ " obtidos a partir da análise de amostras de superfície de carcaças bovinas, colhidas após a lavagem e depois de 24 horas sob refrigeração.

\begin{tabular}{lccr}
\hline Determinação & Pós-lavagem & Pós-refrigeração & Valorde “t” \\
\cline { 2 - 3 } & $\mathrm{UFC} / \mathrm{cm}^{2}$ & $\mathrm{UFC} / \mathrm{cm}^{2}$ & \\
\hline Micro-organismos mesófilos & $1,8 \times 10$ & $1,3 \times 10$ & $0,49^{\mathrm{NS}}$ \\
Micro-organismos psicrotróficos & $6,4 \times 10$ & $1,6 \times 10^{2}$ & $-1,72^{\mathrm{NS}}$ \\
Staphylococcus sp. & $3,5 \times 10$ & $5,2 \times 10$ & $-1,00^{\mathrm{NS}}$ \\
\hline
\end{tabular}

$\mathrm{UFC} / \mathrm{cm}^{2}$ - Unidades Formadoras de Colônias por $\mathrm{cm}^{2}$.

NS - não significativo no nível de $5 \%$ de probabilidade (p.> 0,05). 
BARRA, A.J. Valores de $p H$ e número de microrganismos psicrotróficos em carne bovina. 1980. 63p. Dissertação (Mestrado) - Faculdade de Veterinária, Universidade Federal Fluminense, Niterói, 1980.

DESMARCHELIER, P.M.; HIGGS, G.M.; MILLS, L.; SULLIVAN, A.M.; VANDERLINDE, P.B. Incidence of coagulase positive Staphylococcus on beef carcasses in three Australian abattoirs. International Journal of Food Microbiology, v.47, p.221-229, 1999.

DICKSON, J.S. Reduction of bacteria attached to meat surfaces by washing with selected compounds. Journal of Food Protection, v.51, n.11, p.869-873, 1988.

DOWDY, S.; WEARDEN, S. Statistics for Research. 2.ed. New York: Wiley Interscience Publication, 1991. 629p.

GARCIA-LÓPEZ, M.L.; PRIETO, M.; OTERO, A. The physiological attributes of Gram-negative bacteria associated with spoilage of meat and meat products. In: DAVIES, A.; BOARD, R. (Ed.). The microbiology of meat and poultry. London: Blackie Academic and Professional, 1998. p.1-34.

GIL, J.I. Manual de inspeção sanitária de carnes. 2.ed. Lisboa: Fundação Calouste Gulbenkian, 2002. 485p.

ICMSF - International Commission on Microbiological Specification for Food. Microrganisms in Food. I - Their significance and methods of enumeration. 2ed. Toronto: University of Totonto Press, 2000.439p.

INGRAM, M.; ROBERTS, T.A. The microbiology of the red meat carcass and the slaughterhouse. Journal of the Royal Society of Health, v.96, n.6, p.270-276, 1976.

LAMBERT, A.D.; SMITH, J.P.; DODDS, K.L. Shelf life extension and microbiological safety of fresh meat. A review. Food Microbiology, v.8, n.4, p.267-97, 1991.

LE LOIR, Y.; BARON, F.; GAUTIER, M. Staphylococcus aureus and food poisoning. Genetics and Molecular Research, v.2, n.1, p.63-76, 2003. Disponível em: <http:/ /www.funpecrp.com.br/gmr>. Acesso em: 25 set. 2005.

MADDEN, R.H.; MURRAY, K.A.; GILMOUR, A. Determination of the principal points of product contamination during beef carcass dressing processes in Northern Ireland. Journal of Food Protection, v.67, n.7, p.1494-1496, 2004.

PHILLIPS, D.; SUMNER, J.; ALEXANDER, J.F.; DUTTON, K.M. Microbiological quality of Australian beef. Journal of Food Protection, v.64, n.5, p.692-696, 2001.

PORTO, E. Aspectos microbiológicos da refrigeração. Revista Nacional da Carne, v.7, p.84-93, 1997.

ROÇA, R.O.; SERRANO, A.M. Operações de abate de bovinos. Higiene Alimentar, v.8, n.34, p.14-20, 1994.

ROÇA, R.O.; SERRANO, M.A. Abate de bovinos: alterações microbianas da carcaça. Higiene Alimentar, v.9, n.35, p.8-12, 1995.

ROSEC, J.P.; GUIRAUD, J.P.; DALET, C.; RICHARD, N. Enterotoxin production by staphylococci isolated from foods in France. International Journal of Food Microbiology, v. 35, p. 213-221, 1997.

SUMNER, J.; PETRENAS, E.; DEAN, P.; DOWSETT, P.; WEST, G.; WIERING, R.; RAVEN, G. Microbial contamination on beef and sheep carcases in South Australia. International Journal of Food Microbiology, v.81, n.3, p.255-260, 2003.

SOFOS, J.N.; KOCHEVAR, S.L.; BELLINGER, R.G.; BUIGE, D.R.; HANCOCK, D.D.; INGHAM, S.C.; MORGAN, J.B.; REAGAN, J.O.; SMITH, G.C. Sources and extent of microbiological contamination of beef carcasses in seven United States slaughtering plants. Journal of Food Protection, v.62, n.2, p.140-145, 1999.

VANDERLINDE, P.B.; SHAY, B.; MURRAY, J. Microbiological quality of Australian beef carcass meat and frozen bulk packed beef. Journal of Food Protection, v.61, n.4, p.437-443, 1998.

ZWEIFEL, C.; STEPHAN, R. Microbiological monitoring of sheep carcass contamination in three swiss abattoirs. Journal of Food Protection, v.66, n.6, p.946-952, 2003.

Recebido em 27/11/08

Aceito em 21/5/10 